\title{
Development of Value Added Products from Bael Fruit (Aegle marmelos)
}

\author{
K.Y. Ullikashi ${ }^{1 *}$, M.R. Kammar ${ }^{2}$ and Sudeep R. Lokapure ${ }^{3}$ \\ ${ }^{1}$ Department of Home science, Agricultural extension unit, Koppal, Karnataka, India \\ ${ }^{2}$ Department of Home science, Krishi Vigyan Kendra, Bagalkot, Karnataka, India \\ ${ }^{3}$ Department of Biochemistry, Goa Medical College, Bambolim-Goa, India \\ *Corresponding author
}

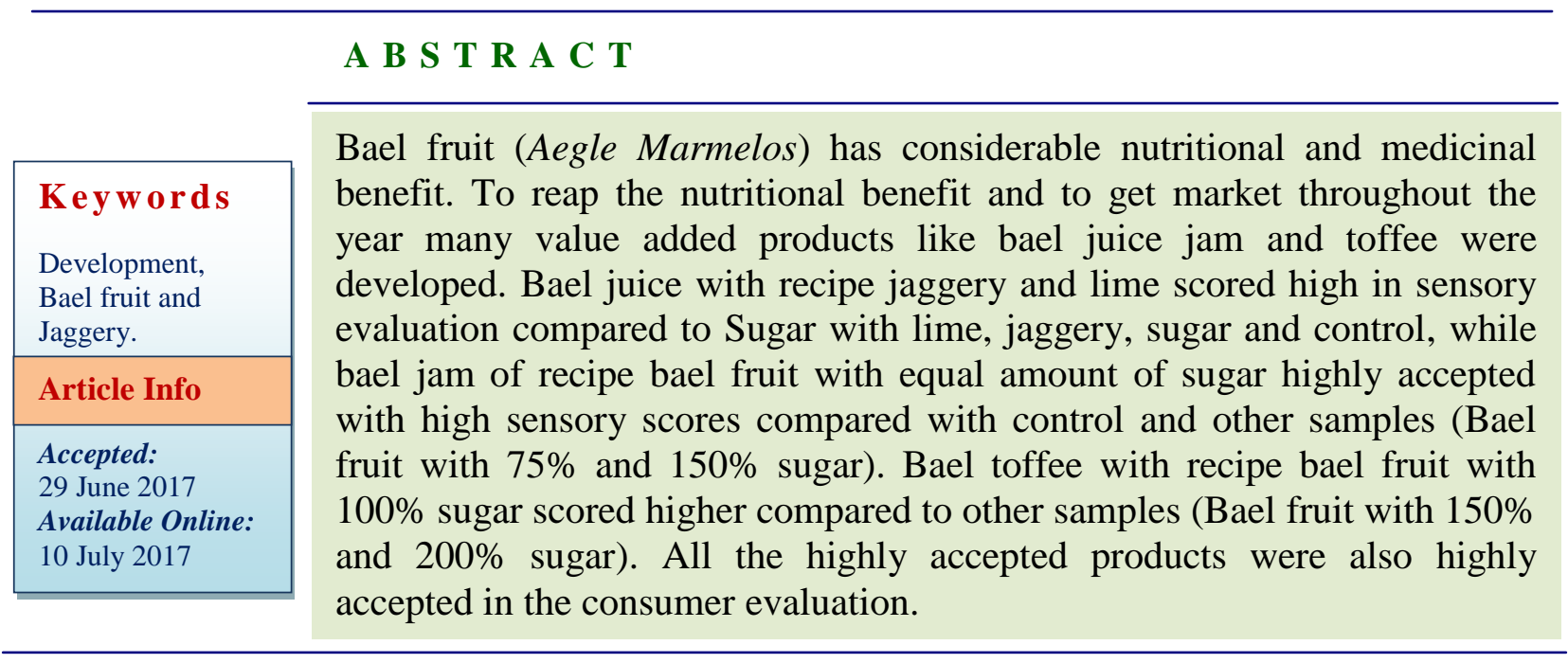

\section{Introduction}

Vegetables and fruits provide health and nutrition promoting compounds in human diet. Their constituents prevent disease through several mechanisms and thus increase one's life span and the quality of health and life. Among the under-utilized fruits, Bael fruit (Aegle Marmelos) occupies an important place. Its scientific name is Aegle Marmelos, while it belongs to family Rutaceae and is commonly known as Bael, Bengal Quince, Indian Bael, Wood Apple, Matoom etc.,

This fruit bearing tree is found in dry forests, hills and plains of Myanmar, Pakistan, Bangladesh, Nepal, Vietnam Laos, Cambodia as well as Sri Lanka, Northern Malaya, Java and in Philippines and in India it is found in Uttar Pradesh, Madhya Pradesh, Orissa, Bihar, West Bengal and Tamil Nadu.

The tree, which is the only species in the genus Aegle, glows up to 18 meters tall with throns and fragrant flowers. The plant easily with stands long periods of drought which are needed for better fruit yield. It grows in all types of soil, climate and require little care when established.

The tree is deciduous with trifoliate aromatic leaves. The spines are straight, strong, auxiliary and about $2.5 \mathrm{~cm}$ in length. The leaflets are 3 to5 and ovate lanceolate, the 
laterals one being sessile and the terminal ones are long petioled. The flowers are $3 \mathrm{cms}$ across, greenish, white and sweet scented. The fruit is nearly spherical and 5 to $15 \mathrm{~cm}$ in diameter. The rind of fruit is grey or yellow and the pulp is sweet, thick, aromatic, gelatinous and orange in colour.

The pulp has numerous seed which are densely covered with fibrous hairs and are oblong and flat. The skin of some forms of the fruit is so hard it must be cracked with a hammer (Phanikumar H.K., 2010).

The bael fruit pulp contains many functional and bioactive compounds such as carotenoids, phenolics, alkaloids, coumarins, flavonoids, terpenoid and other antioxidants which may protect us against chronic disease.

In addition, many researchers reported that it also contain many vitamins and minerals including Vitamin C, Vitamin A, thiamine, riboflavin, niacin, calcium and phosphorus.

There are many trace elements in the body that directly or indirectly participate in metabolism and play an essential role in it.

More than $25 \%$ of the enzymes in the body require metals for activation and to function properly in metabolism, of these metals, iron, magnesium and zinc have been identified as helping to improve cognitive functions in school children's (Tropical fruits of Srilanka, Department of Agriculture, Sri Lanka)

The bael fruit is of considerable medicinal value when it just begins to ripen. The ripe fruit is aromatic, astringent, cooling and laxative.

The unripe or half ripe fruit is astringent, stomatic (a drug that strengthens the stomach and promotes it action), antiscorbutic (a drug which prevents or cures scurvy) and digestive.
The fruit is said to act as a tonic for heart and brain. It is best given in sub-acute or chronic cases of diarrhoea and dysentery and in irritation of the alimentary canal. Also baels are mainly used in the treatment of bacillary dysentery as it helps to remove constipation which hinders the healing of ulcerated surfaces of intestine. The ripe fruit is prescribed in intestinal disorders and certain terms of dyspepsia (indigestion), characterized by alternate constipations and diarrhoea. (Trophical fruits of Srilanka, Department of Agriculture, Sri Lanka).

Though it has considerable medicinal and nutritional benefit due to lack of knowledge of value addition and seasonal bound market farmers are neglecting the fruit.

Hence, a study was planned to develop and asses its consume acceptability of value added products such as juice, jam and toffee from the bael fruits, which not only give the solution to the marketing throughout the year for the farmers but also they can be utilize its nutritional benefits.

The main objectives of this study to develop the value added products such as juice, jam and toffee and also to assess the consumer acceptability.

\section{Materials and Methods}

The ripen bael fruits are selected and procured from ARS, Hagari Farm, Bellary and farmers' fields of Hulikere village Kudligi taluk, Bellary district.

\section{Development of value added products}

Different value added products such as juice, jam, toffee were developed and standardized interms of ingredients combinations were evaluated organoleptically by a panel of semi trained judges panes of ARS and KVK, 
Hagari, Bellary using nine point hedonic scale.

Most accepted products were used for the consumer evaluation. They were served to heterogeneous group of consumer and record their opinion and reviews about the product as "like", "disliked" or "neutral".

\section{Value added products from bael}

\section{Bael juice}

Bael fruit pulp is extracted with water and mixed with different ingredients like sugar, sugar + lime, jaggery and Jaggery + lime with flavouring component cardmom powder.

\section{Bael jam}

Bael fruit pulp is extracted with water and cooked with adding different combination of sugar $(75 \%, 100 \% \& 150 \%)$ for 20 minutes. Lime juice is added to set pectin. After 20 minutes cooking the jam is tested for the jam consistency (Soft ball stage).

\section{Bael toffee}

Bael fruit pulp is extracted with water and cooked for 20 minutes with adding different combination of sugar $(100 \%, 150 \%$ $\& 200 \%)$.After 20 minutes in to cooking ghee is poured in thick bottom pan with cooked pulp, corn flour, milk powder and citric acid is added by dissolving in water.After adding the mixture is cooked for 20 minutes and consistency is tested (Soft ball stage).

All the products were organoleptically evaluated by comparing control recipe.

\section{Results and Discussion}

Bael fruit has considerable medicinal and nutritional benefit (Table 1). Since it was seasonal fruit there is need to develop value added products to reep it's not only nutritional and to get market throughout the year.

Value added products like bael juice, jam and toffee is planned to develop in this study.

\section{Acceptability of value added bael products}

Figure 1 shows the acceptability of value added bael product bael juice. Various combination have been tried and compared with control recipe. Among the samples sample no 4 bael fruit with jaggery and lime accepted with higher sensory scores [color-7, flavour-6.4, consistency-7.1, taiste-7.4 and over all acceptability-7.2 (Table 2)].

Though sample- 2 sugar with lime has scored better but the combination of jaggery with lime due to typical jaggery taiste has been appreciated most.

Figure 2 shows the acceptability of bael jam from bael fruit. Bael fruit with equal amount of sugar (sample-2) highly accepted with high sensory scores compared with control and other samples [color-7.8, flavor -7.9, texture7.9, taiste-7.6 and over all acceptability-7.3 (Table 3)]. Though the sample-1 score better but due to glossy appearance and accepted flavour, texture of sample-2 scored higher.

Figure 3 shows the acceptability of bael toffee from the bael fruit. Among three samples,sample-1 bael fruit with equal amount of sugar (100\%) highly accepted with high sensory scores of taste and over allacceptability $\quad(7.2 \quad$ and $\quad 7.1$ respectively).Though sample-2 (sugar-150\%) and sample-3 (sugar-200\%) scored better sensory attributes in terms of color and flavour but due to accepted texture of toffee and taste sample- 1 has accepted most in the toffees, whereas due to poor texture of sample-2 and 3 they scored less (Table 4). 
Table.1 Nutritive value of bael per $100 \mathrm{~g}$ edible portion

\begin{tabular}{|l|l|}
\hline Nutrients & Amount \\
\hline Proteins & $1.8 \mathrm{gm}$ \\
\hline Carbohydrates & $31.8 \mathrm{gm}$ \\
\hline Fats & $0.3 \mathrm{gm}$ \\
\hline Moisture & $64.2 \mathrm{gm}$ \\
\hline Fiber & $2.2 \mathrm{gm}$ \\
\hline Vitamins & $1.19 \mathrm{mg}$ \\
\hline Riboflavin & $1.1 \mathrm{mg}$ \\
\hline Niacin & $0.13 \mathrm{mg}$ \\
\hline Thiamin & $55 \mathrm{mg}$ \\
\hline Vitamin A & $8 \mathrm{to} 60 \mathrm{mg}$ \\
\hline Vitamin C & \multicolumn{2}{|l|}{} \\
\hline Minerals & $85 \mathrm{mg}$ \\
\hline Calcium & $50 \mathrm{mg}$ \\
\hline Phosphorus & $600 \mathrm{mg}$ \\
\hline Potassium &
\end{tabular}

Table.2 Sensory evaluation of value added product bael juice

\begin{tabular}{|l|l|l|l|l|l|l|}
\hline SI no & Products & color & Flavor & consistency & Taste & Over all acceptability \\
\hline 1 & Control & 6.6 & 6.4 & 6.4 & 6.8 & 6.2 \\
\hline 2 & Sample-1 & 5.5 & 5.6 & 5.6 & 5.5 & 5.5 \\
\hline 3 & Sample-2 & 6.6 & 6.6 & 5.8 & 6.3 & 6.6 \\
\hline 4 & Sample-3 & 6.6 & 6.2 & 6.2 & 6.4 & 6.2 \\
\hline 5 & Sample-4 & 7.0 & 6.4 & 7.1 & 7.4 & 7.2 \\
\hline
\end{tabular}

Table.3 Sensory evaluation of value added product bael jam

\begin{tabular}{|l|l|l|l|l|l|l|}
\hline SI no & Products & color & Flavor & Texture & Taste & Over all acceptability \\
\hline 1 & Control & 7.8 & 7.6 & 7.4 & 7.4 & 7.5 \\
\hline 2 & Sample-1 & 7.3 & 7.2 & 7.1 & 7.4 & 7.0 \\
\hline 3 & Sample-2 & 7.8 & 7.9 & 7.9 & 7.6 & 7.3 \\
\hline 4 & Sample-3 & 6.9 & 6.9 & 6.7 & 7.5 & 7.0 \\
\hline
\end{tabular}

Table.4 Sensory evaluation of value added product bael toffee

\begin{tabular}{|l|l|l|l|l|l|l|}
\hline Sl no & Products & color & Flavor & Texture & Taste & Over all acceptability \\
\hline 1 & Control & 7.3 & 7.6 & 7.4 & 7.4 & 7.4 \\
\hline 2 & Sample-1 & 6.1 & 6.3 & 6.3 & 7.2 & 7.1 \\
\hline 3 & Sample-2 & 6.6 & 6.0 & 5.2 & 5.4 & 6.2 \\
\hline 4 & Sample-3 & 6.7 & 5.5 & 5.3 & 5.8 & 6.1 \\
\hline
\end{tabular}


Table.5 Consumer evaluation of bael products

\begin{tabular}{|l|l|l|l|l|}
\hline SI no & Products & Liked & Disliked & neutral \\
\hline $\mathbf{1}$ & Bael juice & $\mathbf{1 1 3}$ & - & $\mathbf{7}$ \\
\hline $\mathbf{2}$ & Bael jam & $\mathbf{1 1 0}$ & - & $\mathbf{1 0}$ \\
\hline $\mathbf{3}$ & Bael toffee & $\mathbf{1 0 7}$ & - & 13 \\
\hline
\end{tabular}

Fig.1 Acceptability of value added bael product bael juice

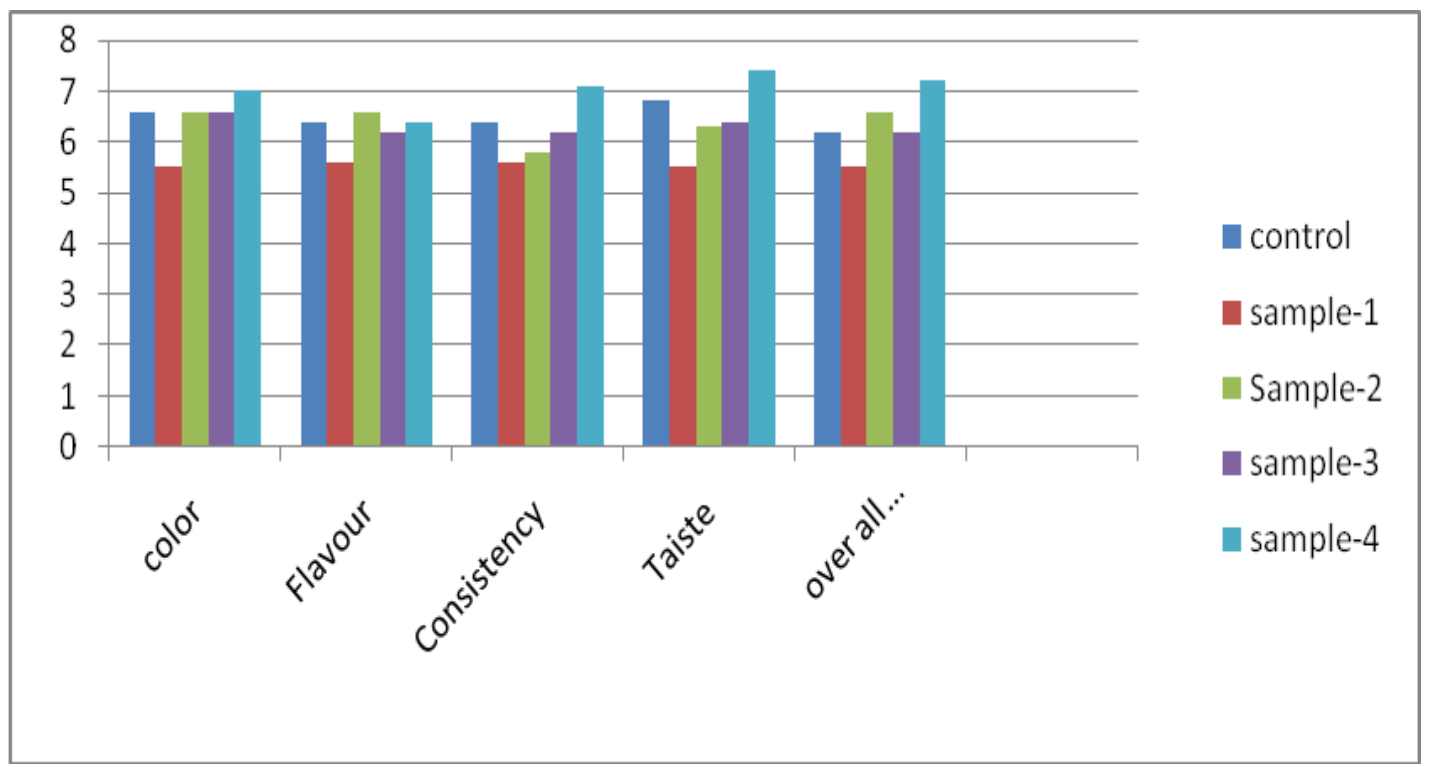

Sample-1: Bael fruit with sugar + cardmom powder; Sample-2: Bael fruit with sugar + lime + cardmom powder; Sample-3: Bael fruit with jaggery + cardmom powder; Sample-4: Bael fruit with jaggery + lime + cardmom powder

Fig.2 Acceptability of value added bael product bael jam

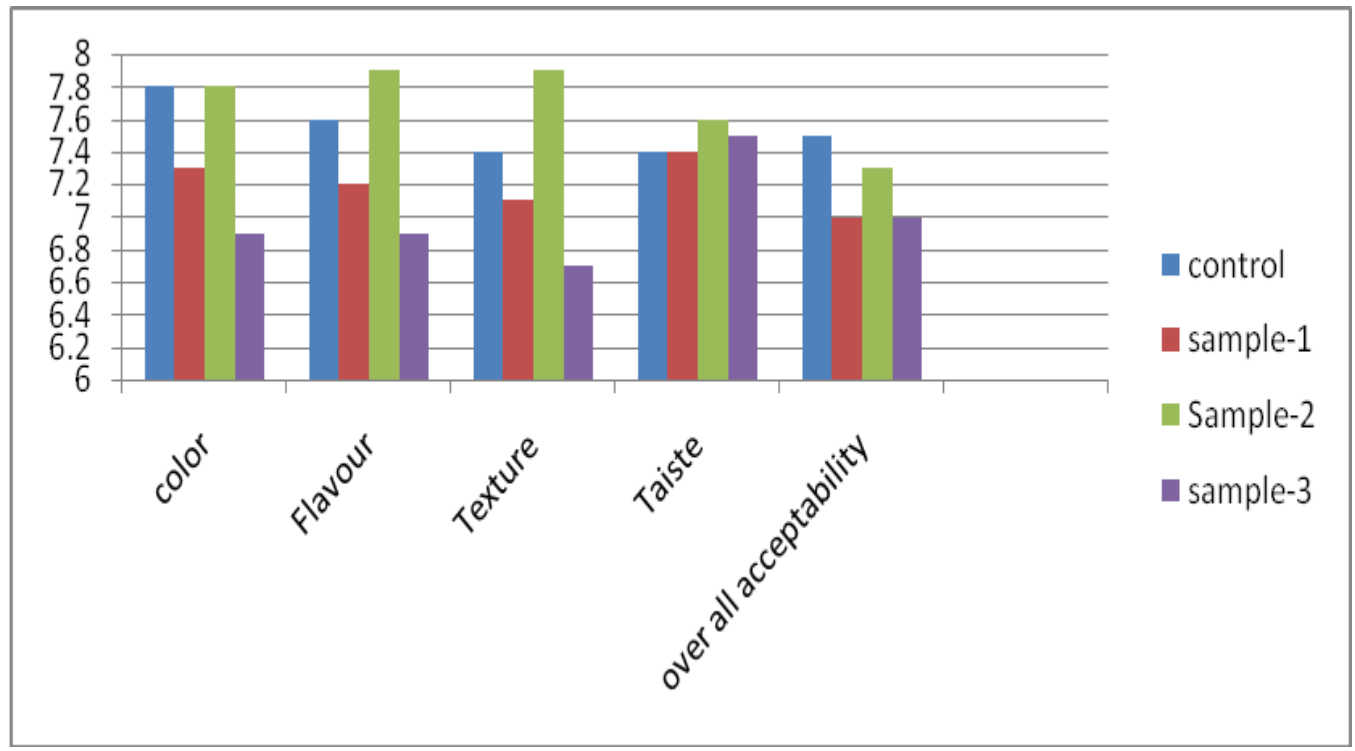

Sample-1: Bael fruit with 75\%sugar+lime; Sample-2: Bael fruit with 100\%\$ sugar + lime; Sample-3: Bael fruit with $150 \% \$$ sugar + lime; 
Fig.3 Acceptability of value added bael product bael toffee

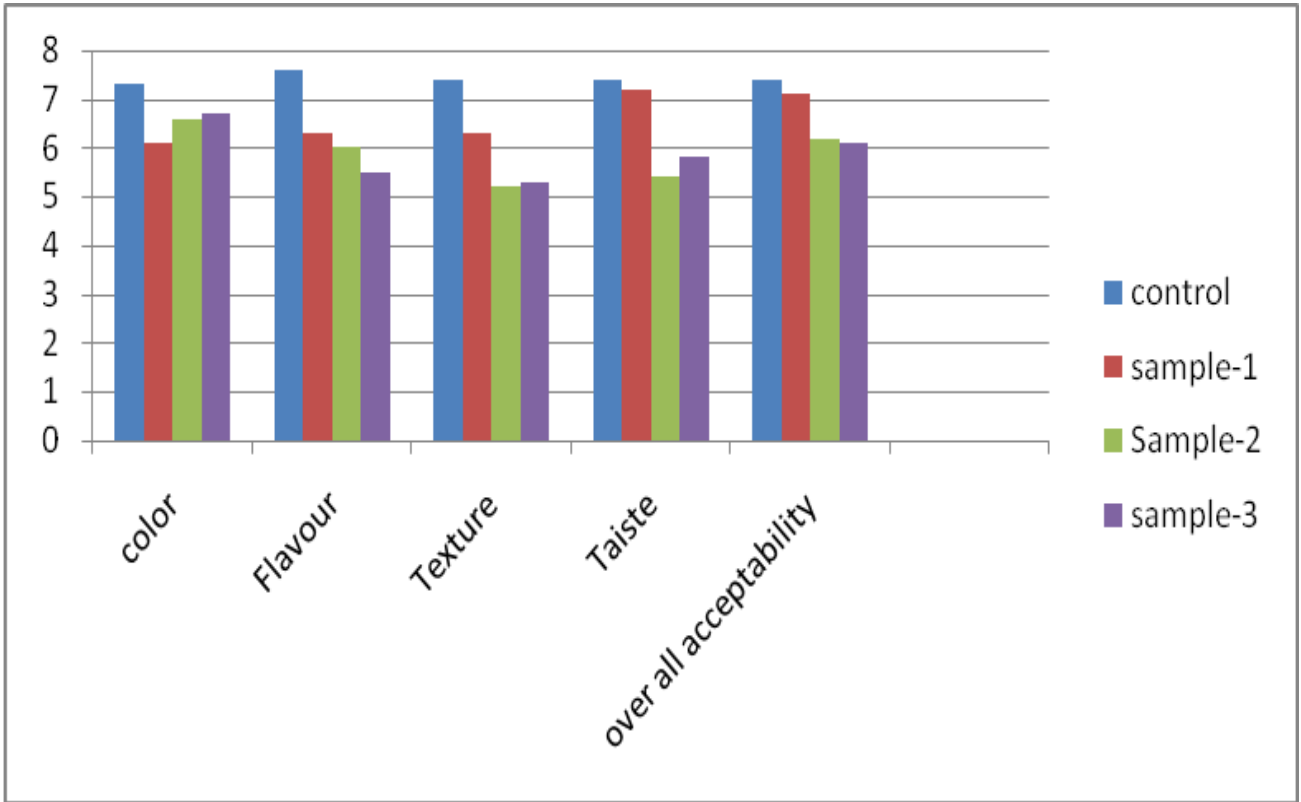

Sample-1: Bael fruit with 100\%\%sugar + ghee + cornflour + milk powder + lime Sample-2: Bael fruit with $150 \%$ sugar + ghee + cornflour + milk powder + lime Sample-3: Bael fruit with $200 \%$ sugar + ghee + cornflour + milk powder + lime

Fig.4 Consumer evaluation of bael products

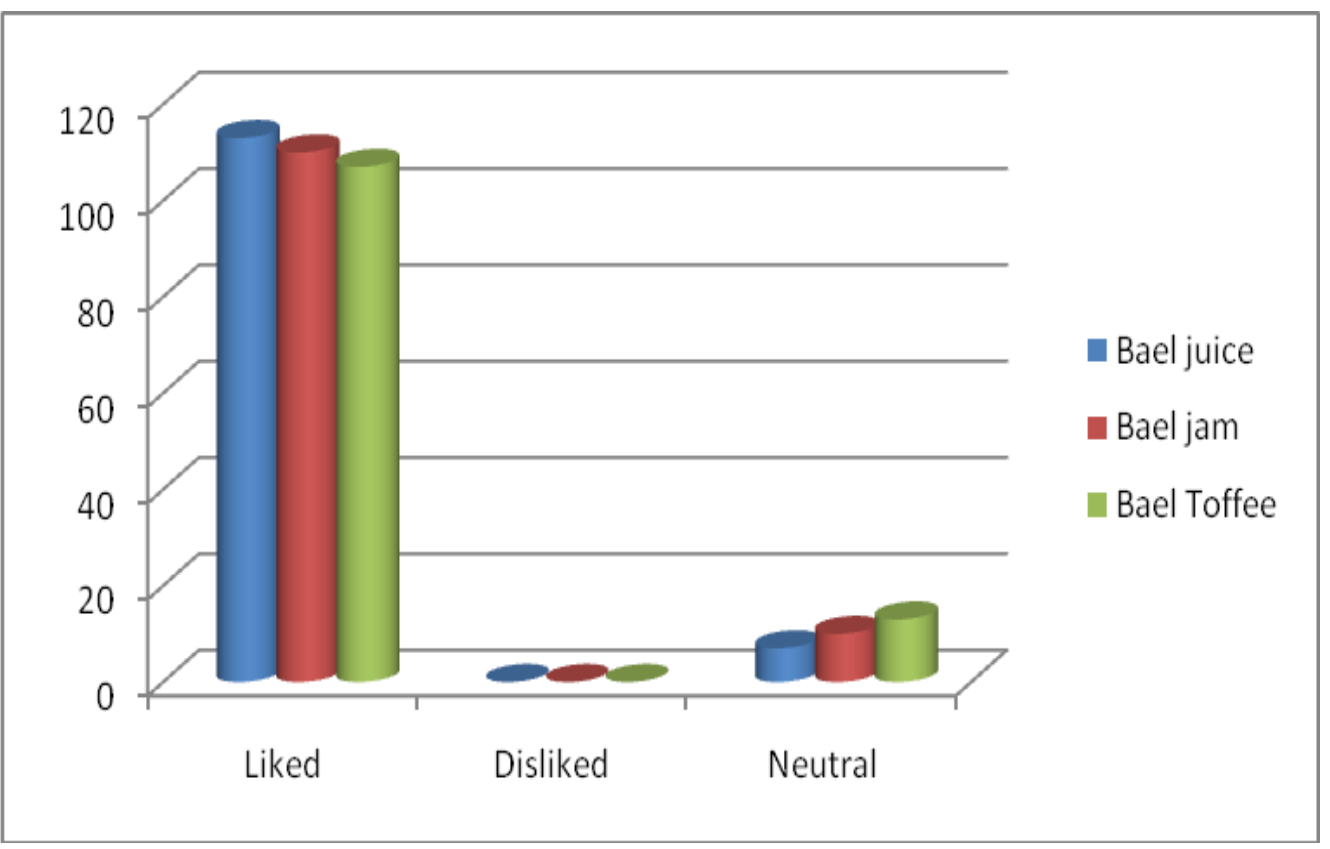




\section{Bael Juice}

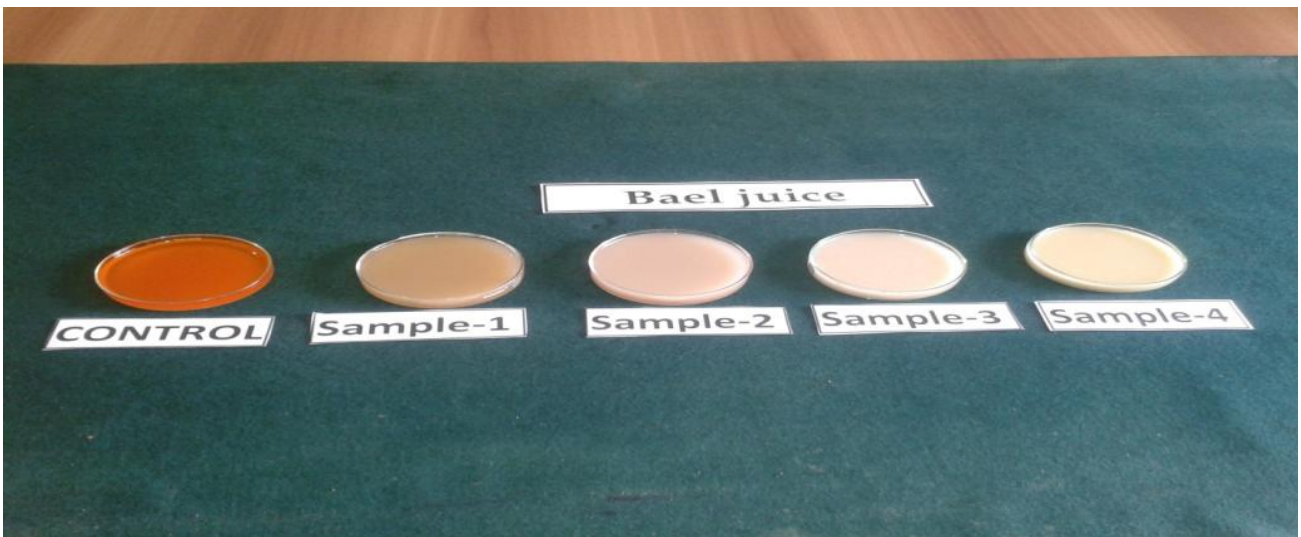

Sample-1: Bael fruit with sugar + cardmom powder

Sample-2: Bael fruit with sugar + lime + cardmom powder

Sample-3: Bael fruit with jaggery + cardmom powder

Sample-4: Bael fruit with jaggery + lime + cardmom powder

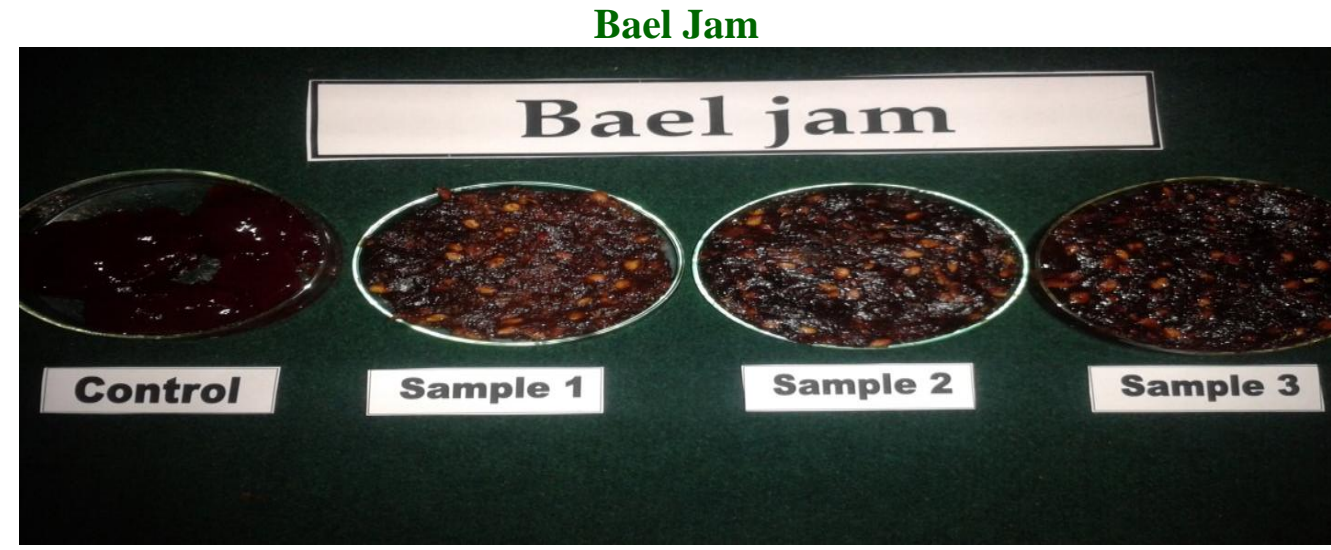

Sample-1:-Bael fruit with 75\%sugar+lime

Sample-2:- Bael fruit with $100 \% \$$ sugar + lime

Sample-3:- Bael fruit with $150 \% \$$ sugar + lime

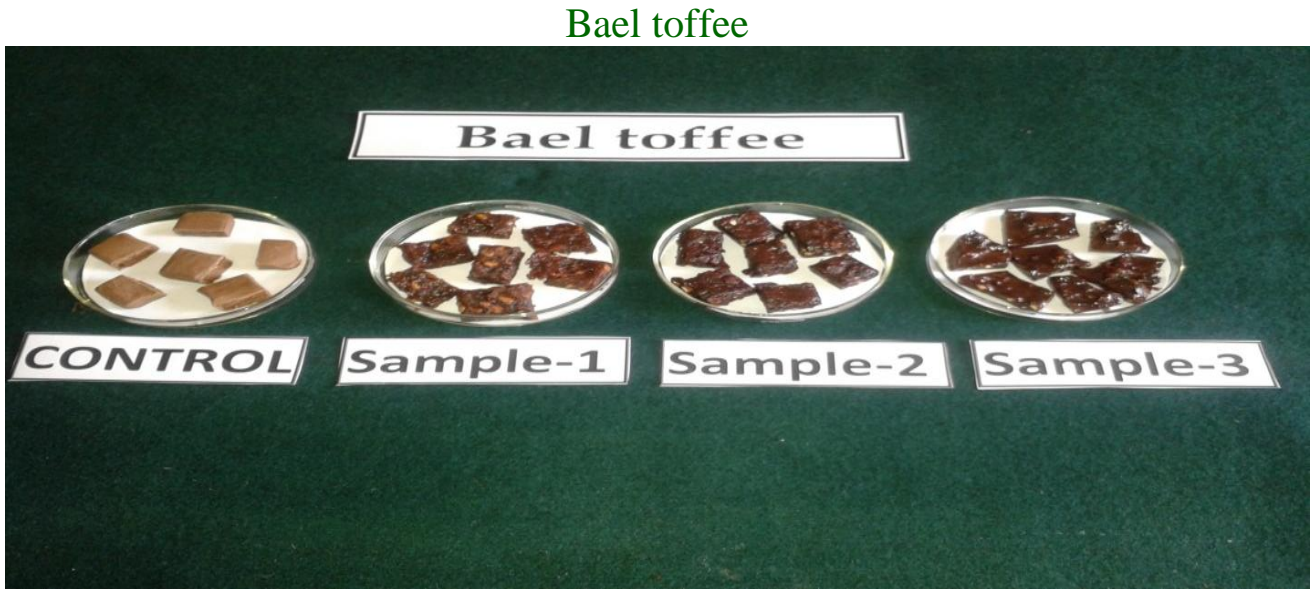

Sample-1:-Bael fruit with 100\%\%sugar + ghee + cornflour + milk powder + lime

Sample-2:- Bael fruit with $150 \%$ sugar + ghee + cornflour + milk powder + lime

Sample-3:- Bael fruit with $200 \%$ sugar + ghee + cornflour + milk powder + lime 
Almost similar results were observed by Ivi Chakraborthy et al., (2011), Rao (2000) and Phanikumar (2010).

\section{Consumer evaluation}

Bael juice with jaggery + lime, bael jam and tofffee with equal amount of sugar which scored higher in organoleptic evaluation are selected for consumer evaluation. About 120 heterogenous group of consumers are evaluated the products as liked, disliked and neutral. About $94 \%$ of the consumers (113) liked the bael juice and $6 \%$ of the consumer (7) reviewed neutral to the juice.92\% of the consumer (110) liked the bael jam, whereas $8 \%$ of the consumer (10) expressed neutral reaction to the product. $89 \%$ of the consumer liked bael toffee and $11 \%$ of the consumer (13) showed neutral reaction to the product (Figure 4 and Table 5).None of the consumer disliked the products.
In conclusion, Bael fruit has considerable nutritional and medicinal benefit. Bael juice with recipe jiggery and lime, bael jam and toffee of combination of equal amount of sugar organoleptically scored higher and accepted. Above products also highly accepted in the consumer evaluation.

\section{References}

Ivi chakraborthy, Chaurasiya. K., and Saha. J (2011), Journal of food science and technology Vol.48 (6).p.no.750-754

Phanikumar. H.K., 2010, Value added products from bael fruit, Science Tech Entrepreneur.

Tropical fruits of Sri Lanka, Department of Agriculture, Sri Lanka.

Rao. V.S., (2000), Post-harvest technology and value addition in fruits, winter school manual, central research institute for dryland agriculture, Hyderabad.

\section{How to cite this article:}

Ullikashi, K.Y., M.R. Kammar and Sudeep R. Lokapure. 2017. Development of Value Added Products from Bael Fruit (Aegle marmelos). Int.J.Curr.Microbiol.App.Sci. 6(7): 2652-2659. doi: https://doi.org/10.20546/ijcmas.2017.607.374 